\title{
COMPARISON OF MAMMOGRAPHY AND ULTRASOUND COMBINED VERSUS ULTRASOUND ALONE IN EARLY EVALUATION OF SYMPTOMATIC BREAST CANCERS IN PAKISTAN
}

\author{
Razia Bano ${ }^{1}$, Huma M. Khan², Ayesha Ehsan ${ }^{1}$, Awais A. Malik², Shahper Aqeel ${ }^{3}$, \\ Amina I. Khan ${ }^{2}$ \\ ${ }^{1}$ Department of General Surgery, Combined Military Hospital, Rawalpindi, Pakistan, ${ }^{2}$ Department of Surgical \\ Oncology, Shaukat Khanum Memorial Cancer Hospital and Research Centre, Lahore, Pakistan, ${ }^{3}$ Department of \\ Radiology, Shaukat Khanum Memorial Cancer Hospital and Research Centre, Lahore, Pakistan \\ Received: 7 August 2017 / Accepted: 19 December 2017
}

\begin{abstract}
Purpose: The purpose of this study was to detect diagnostic accuracy of mammography and ultrasound combined versus ultrasound alone in early evaluation of symptomatic breast lesions.

Materials and Methods: All new patients who presented to the breast clinic with symptomatic breast lesions, during the year 2012, were included in the study. A total of 695 patients were registered. Their clinical findings, mammogram, ultrasound and histopathology were reviewed.

Results: Mammogram and ultrasound combined detected 693 (99.71\%) lesions in total. Mammogram failed to detect lesions in $1.43 \%$ of patients, whereas the failure rate of ultrasound was $0.43 \%$. The incidence of microcalcifications on mammogram was $19.13 \%$.

Conclusion: Ultrasound is a useful tool in the initial evaluation of symptomatic breasts. For places such as Pakistan where mammogram is not available at every centre, ultrasound can be used as an effective alternative for the assessment of symptomatic breast lesions.
\end{abstract}

Key words: Breast cancer, mammography, ultrasound

\section{Introduction}

Breast cancer is the most common cause of cancer-related deaths amongst the female gender. Amongst the Asian countries, Pakistan has the highest risk of breast cancer; one out of every nine Pakistani women carries the risk of breast cancer. ${ }^{[1,2]}$ Breast cancer arises from the inner lining of the ductal system (ductal carcinoma) or it arises from the lobules (lobular carcinoma). ${ }^{[3]}$ Incidence of breast cancer in Pakistan was $45.9 \%$ according to data of a single institution. In a developing country such as Pakistan, mammography screening programs are not available due to limited resources since mammography is costly; therefore, only affording patients on individual basis can undergo screening mammograms. ${ }^{[4]}$ Presentation is usually

Correspondence: Dr. Razia Bano, Department of General Surgery, Combined Military Hospital, Rawalpindi, Pakistan.

Email: raazia240@gmail.com with palpable breast lesions or even locally advanced; this is due to the lack of awareness and affordability for diagnosis and treatment. ${ }^{[5]}$ Breast imaging is indicated for screening purposes, evaluation of symptomatic breast lumps and planning for the management of breast cancer. Mammogram and ultrasound are the most common modalities; magnetic resonance imaging (MRI) is used less commonly. Other modalities include Scintimammography, single-photon emission computed tomography and positron emission tomography. ${ }^{[6,7]}$

The aim of breast imaging is to detect breast cancer in its earliest stage so that curative treatment can be planned. The earlier the detection, the better the survival. Mammogram and ultrasound are the most common investigations for screening and evaluation of breast lesions. The incidence of breast cancer-related deaths can be reduced by $30 \%$, in screening of patients. Screening mammogram can 
detect suspicious lesions such as micro calcifications, architectural distortion and asymmetry, even before the lump becomes palpable. ${ }^{[8]}$

Breast imaging reporting and data system (BIRADS) is a risk assessment tool in mammography, ultrasound or MRI. There are six categories of BIRADS as follows; ${ }^{[9,10]}$

- $\quad$ BIRADS 0 - Incomplete

- $\quad$ BIRADS I - Negative

- $\quad$ BIRADS II - Benign findings

- $\quad$ BIRADS III - Probably benign

- $\quad$ BIRADS IV - Suspicious abnormality

- IV A - Low suspicion of malignancy

- $\quad$ IV-B - Intermediate suspicion

- $\quad$ IV C - Moderate suspicion

- BIRADS V - Highly suggestive of malignancy

- $\quad$ BIRADS VI - Known biopsy-proven malignancy.

Mammography uses low-energy X-rays to examine the breast. Ultrasound differentiates between solid and cystic lesions. When mammogram is combined with ultrasound, the diagnostic accuracy increases. ${ }^{[8,9]}$ However,mammography is expensive and not commonly available in Pakistan. Ultrasound, on the other hand, is a more commonly available modality for detecting breast lesions. The purpose of our study is to compare the diagnostic accuracy of mammogram and ultrasound versus mammogram alone versus ultrasound alone.

\section{Materials and Methods}

Permission from the ethical committee of the hospital was taken for retrieving and publication of data. We retrospectively reviewed the data of all the registered female breast cancer patients during the year 2012 at our institute. Only patients with symptomatic breast lesions and proven cancers on final pathology were included. The clinical findings, their mammogram and ultrasound at initial presentation were reviewed from the hospital records. Patients who had undergone incisional or excisional biopsies without prior mammogram were excluded. We also excluded patients who underwent screening breast imaging and were asymptomatic. Patients who visited breast clinics for the evaluation of palpable lumps, lumpiness breast, nipple discharge, skin changes and nipple changes of recent onset were included in the study.
After detailed clinical examination, the patients were subjected to mammogram and ultrasound, ultrasoundguided core biopsy of the suspicious lesion or ill-defined density. These patients had two view mammogram, mediolateral and craniocaudal, followed by ultrasound evaluation of breasts and axillae. Ultrasound examination was performed in the supine position with ipsilateral arm raised. All ultrasound examinations were performed by dedicated breast radiologists. Core biopsy was performed on all patients under ultrasound guidance. At the same occasion, fine-needle aspiration cytology of borderline and suspicious axillary lymph nodes was performed. The age range was $32-68$ years. Patients were divided into two age groups, $<50$ years and 50 and above. Reports of these patients were reviewed by two investigators. Clinical examination, mammograms and ultrasound findings of these patients were compared. Patients who had a mammogram were further divided into five subgroups; patients who had well-defined lesion on mammogram; patients who mass and microcalcifications; patients who only microcalcifications; patients who had ill-defined density, asymmetry, architectural distortion, vague density or area of thickening; and patients who negative mammogram. Sonographic findings were grouped into positive and negative ultrasounds.

\section{Results}

A total of 695 patients constitute the study population. The age range was 32-68 years, $365(51.6 \%)$ patients were $685(98.56 \%)$ patients whereas ultrasound was positive in 692 or $(99.5 \%)$ patients.

Of the 10 patients missed on mammogram, 8 were picked up by ultrasound. Only three patients had a failure to demonstrate lesion on ultrasound, one of which was demonstrated on mammogram. Both mammogram and ultrasound were negative in two cases, but these patients had Paget's disease of the nipple.

Details of mammogram and ultrasound findings in both the age groups are illustrated in Table 1. Mammogram was a better modality for detecting lesions in the elderly as it missed $7(1.0 \%)$ lesions in younger age group and only $3(0.43 \%)$ lesions in the old age group. Younger patients had dense breast and when subjected to additional ultrasound, lesions were well demonstrated in all the 


\section{Table 1: Mammogram and ultrasound findings according to age groups}

\begin{tabular}{|c|c|c|}
\hline Imaging modality & $\begin{array}{c}\text { Age } \\
<50 \text { years }(\%)\end{array}$ & $\begin{array}{c}\text { Age } \\
>50 \text { years }(\%)\end{array}$ \\
\hline \multicolumn{3}{|l|}{$\begin{array}{l}\text { Mammogram } \\
\text { findings }\end{array}$} \\
\hline Mass only & $254(36.54)$ & 241 (34.67) \\
\hline $\begin{array}{l}\text { Mass and micro- } \\
\text { calcifications }\end{array}$ & 62 (8.92) & $63(9.06)$ \\
\hline $\begin{array}{l}\text { Asymmetry/archi- } \\
\text { tectural distortion }\end{array}$ & $37(5.32)$ & $20(2.87)$ \\
\hline $\begin{array}{l}\text { Microcalcifica- } \\
\text { tions only }\end{array}$ & $5(0.71)$ & $3(0.43)$ \\
\hline Negative & $7(1)$ & $3(0.43)$ \\
\hline \multicolumn{3}{|l|}{ Ultrasound findings } \\
\hline Positive & $364(52.3)$ & $328(47.19)$ \\
\hline Negative & $1(0.14)$ & $2(0.28)$ \\
\hline
\end{tabular}

Table 2: Mammogram versus ultrasound

\begin{tabular}{l|c}
\hline Modality & No. of patients \\
\hline Mammogram and ultrasound positive & $680(97.84)$ \\
\hline Mammogram negative & $10(1.43)$ \\
\hline Ultrasound negative & $3(0.43)$ \\
\hline Both negative & $2(0.28)$ \\
\hline
\end{tabular}

patients; therefore, in dense breast, ultrasound was more useful.

The incidence of microcalcifications was $19.13 \%$. Patients who had only microcalcifications but no lesion on mammogram, presented with mastalgia and heaviness in the breast, showed an associated mass when subjected to additional ultrasound [Figure 1]. The sensitivity of mammogram alone was $98.84 \%$ and ultrasound $99.8 \%$, and mammogram combined modality had a sensitivity of $100 \%$. Mammogram and ultrasound combined have high detection rate $(99.71 \%$ ), failure rate of USG was $0.43 \%$, while that of mammogram was $1.43 \%$ [Table 2].

\section{Discussion}

Breast cancer is the most common malignant tumours of females. It is one of the five leading causes of cancerrelated deaths in women all over the world ${ }^{[11]}$ Breast cancer is the most common malignancy in Pakistani women, and its incidence is highest amongst the Asian

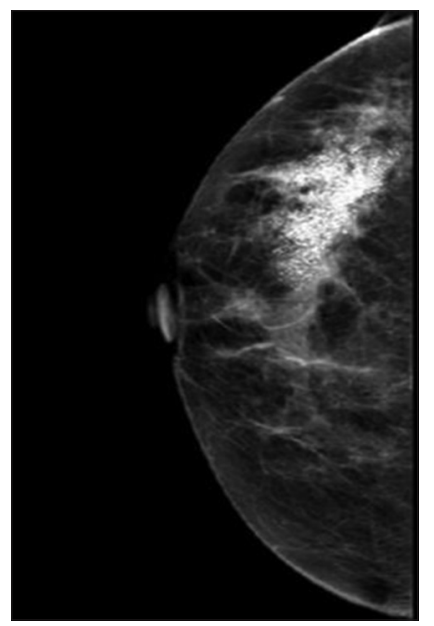

Figure 1: Microcalcifications on mammogram

countries, 2.5 times higher as compared to India and Iran. ${ }^{[12-14]}$ Patients usually present at advanced stages due to lack of awareness or resources. Only a few patients can afford or have access to mammography for detecting breast lesions. ${ }^{[5]}$ About $63 \%$ of patients usually present at stage III or IV. There are few leading hospitals in the country dedicated for cancer treatment. ${ }^{[13]}$ Our institution has a dedicated breast surgery unit. Since most of our patients are those who have symptomatic breast lesions, our study could not be done on generalised population. Therefore, our study included only those patients who presented with symptomatic breasts lesions.

We compared the sensitivity of mammogram and ultrasound alone and in combination of both the modalities. The aim of combining ultrasound with mammogram is to increase the cancer detection rate in the early stages. Our results showed that sensitivity of combined modalities is greater in detection of breast lesions. However, ultrasound was more effective in detecting these lesions as compared to mammogram. For a developing country like Pakistan where the facility of mammography is not easily available, ultrasound may be used as primary imaging modality because it is cost effective and easily available. Osako et al. showed that sensitivity of ultrasound is $100 \%$ in clinically palpable lesions. ${ }^{[15]}$

The results of our study are supported by Gonzaga, who studied the accuracy of ultrasound in evaluation of palpable breast lesions; overall sensitivity of ultrasound was $92.5 \%$, while it was $57.1 \%$ in detection of breast cancers. Positive 
predictive value was $68.1 \%$ and negative predictive value was $99.5 \%$. Study proposed that ultrasound may be used as primary imaging modality in patients under the age of 30 years with palpable lesions. ${ }^{[16]}$ Therefore, it is a reliable tool for the evaluation of palpable breast lesions. Ultrasound is easily assessable for patients, and ultrasound-guided core biopsies are better representatives than blind cores; nowadays, it has become a popular modality in the evaluation of symptomatic breast lesions.

The results of our study are also supported by the findings of McCavert et al. who compared clinical findings with pathology in patients undergoing triple assessments, and their results showed higher sensitivity of mammogram and ultrasound combined as compared to mammogram alone. ${ }^{[17]}$

Moss et al. assessed the ability of mammography and ultrasound in combination to predict whether breast abnormality is benign or malignant in patients with symptomatic breast lesions, and they found that extensive use of ultrasound increases the detection of cancer rate by $14 \%$ in the selected group of patients. ${ }^{[18]}$

Our study was retrospective, so only histopathologyproven cancers were included. Only a single lesion was missed on ultrasound which was detected by mammogram, and stereotactic core was done for biopsy.

Devolli-Disha et al. compared the accuracy of mammography and ultrasound in women with breast symptoms according to age and breast density, their results also support our study and sensitivity and specificity of ultrasound were greater than mammography in patients in younger symptomatic patients with dense breasts. ${ }^{[19]}$

In our study population, ultrasound sensitivity was higher as compared to mammography in patients $<50$ years. Therefore, ultrasound can be used not only in the evaluation of symptomatic breast lesions but also it can be used as a screening tool in selected group of patients, to conserve resources in a developing country like Pakistan. Thomas et al. compared performance of screening mammography, physical examination and ultrasound in 11,130 patients, and they concluded that sensitivity of mammography declines with increasing breast density and addition of ultrasound screening significantly increases the detection of small cancers. ${ }^{[20]}$ The detection benefits of screening ultrasound in high-risk women are now well validated. ${ }^{[21-24]}$

Mammography is very sensitive in the detection of microcalcifications, but because benign calcifications cannot always be distinguished from those malignant, the specificity of mammography remains low. Only $20-35 \%$ of the cases will prove to be cancerous after stereo wire localisation biopsy of clustered microcalcifications. High-frequency ultrasound can detect masses associated with microcalcifications. Benign microcalcifications are not detected on ultrasound because they occur in breast parenchyma. Moon et al. carried out a prospective study to determine whether ultrasound performed with a highfrequency transducer can demonstrate breast masses associated with mammographically detected clustered microcalcifications without mass density. At ultrasound, breast masses associated with mammographically detected microcalcifications were seen in $45(45 \%)$ of 100 cases, $23 \%$ in benign and $82 \%$ in malignant microcalcifications. ${ }^{[25]}$

In our study, only eight patients had clustered microcalcifications but no mass on mammogram; however, ultrasound in addition to mammogram detected these calcifications with well-defined mass. Ultrasoundguided core biopsy was performed and these were biopsyproven carcinomas.

\section{Conclusion}

Ultrasound has a higher sensitivity for detecting breast lesions as compared to mammogram in younger age group ( $<40$ years). Microcalcifications seen on mammogram need careful evaluation by an additional ultrasound by a experienced radiologist to rule out associated masses. In developing countries such as Pakistan, ultrasound may be used as primary screening modality, especially in younger patients with symptomatic breast lesions.

\section{Conflict of Interest}

The authors declare that they have no conflict of interest.

\section{References}

1. Elsie KM, Gonzaga MA, Francis B, et al. Current knowledge, attitudes and practices of women on breast cancer and mammography at mulago hospital. Pan Afr Med J 2010;5:9. 
2. Sohail S, Alam SN. Breast cancer in Pakistan awareness and early detection. J Coll Physicians Surg Pak 2007;17:711-2.

3. Sariego J. Breast cancer in the young patient. Am Surg 2010;76:1397-400.

4. Badar F, Faruqui ZS, Uddin N, et al. Management of breast lesions by breast physicians in a heavily populated South Asian developing country. Asian Pac J Cancer Prev 2011;12:827-32.

5. Badar F, Faruqui ZS, Ashraf A, et al. Third world issues in breast cancer detection. J Pak Med Assoc 2007;57:137-40.

6. Karellas A, Vedantham S. Breast cancer imaging: A perspective for the next decade. Med Phys 2008;35:4878-97.

7. Lazarus E, Mainiero MB, Schepps B, et al. BI-RADS lexicon for US and mammography: Interobserver variability and positive predictive value. Radiology 2006;239:385-91.

8. Prasad SN, Houserkova D. A comparison of mammography and ultrasonography in the evaluation of breast masses. Biomed Pap Med Fac Univ Palacky Olomouc Czech Repub 2007; 151:315-22.

9. American College of Radiology. Breast Imaging Reporting and Data System Atlas (BI-RADS Atlas). Reston, VA: American College of Radiology; 2003.

10. Morris KT, Vetto JT, Petty JK, et al. A new score for the evaluation of palpable breast masses in women under age 40. Am J Surg 2002;184:346-7.

11. Naeem M, Khan N, Aman Z, et al. Pattern of breast cancer: Experience at lady reading hospital, Peshawar. J Ayub Med Coll Abbottabad 2008;20:22-5.

12. Asif HM, Sultana S, Akhtar N, et al. Prevalence, risk factors and disease knowledge of breast cancer in Pakistan. Asian Pac J Cancer Prev 2014;15:4411-6.

13. Gilani GM, Kamal S, Akhter AS. A differential study of breast cancer patients in Punjab, Pakistan. J Pak Med Assoc 2003;53:478-81.

14. Houssami N, Turner RM. Staging the axilla in women with breast cancer: The utility of preoperative ultrasound-guided needle biopsy. Cancer Biol Med 2014;11:69-77.

15. Osako $\mathrm{T}$, Iwase $\mathrm{T}$, Takahashi $\mathrm{K}$, et al. Diagnostic mammography and ultrasonography for palpable and nonpalpable breast cancer in women aged 30 to 39 years. Breast Cancer 2007;14:255-9.

16. Gonzaga MA. How accurate is ultrasound in evaluating palpable breast masses? Pan Afr Med J 2010;7:1.

17. McCavert M, O'Donnell ME, Aroori S, et al. Ultrasound is a useful adjunct to mammography in the assessment of breast tumours in all patients. Int J Clin Pract 2009;63:1589-94.

18. Moss HA, Britton PD, Flower CD, et al. How reliable is modern breast imaging in differentiating benign from malignant breast lesions in the symptomatic population? Clin Radiol 1999;54:676-82.

19. Devolli-Disha E, Manxhuka-Kërliu S, Ymeri H, et al. Comparative accuracy of mammography and ultrasound in women with breast symptoms according to age and breast density. Bosn J Basic Med Sci 2009;9:131-6.

20. Kolb TM, Lichy J, Newhouse JH. Comparison of the performance of screening mammography, physical examination, and breast US and evaluation of factors that influence them: An analysis of 27,825 patient evaluations. Radiology 2002;225:165-75.

21. Berg WA, Blume JD, Cormack JB, et al. Combined screening with ultrasound and mammography vs mammography alone in women at elevated risk of breast cancer. JAMA 2008;299:2151-63.

22. Berg WA. Beyond standard mammographic screening: Mammography at age extremes, ultrasound, and MR imaging. Radiol Clin North Am 2007;45:895-906, 7.

23. Booi RC, Carson PL, O'Donnell M, et al. Characterization of cysts using differential correlation coefficient values from two dimensional breast elastography: Preliminary study. Ultrasound Med Biol 2008;34:12-21.

24. Lehman CD, Isaacs C, Schnall MD, et al. Cancer yield of mammography, MR, and US in high-risk women: Prospective multi-institution breast cancer screening study. Radiology 2007;244:381-8.

25. Moon WK, Im JG, Koh YH, et al. US of mammographically detected clustered microcalcifications. Radiology 2000;217:849-54. 